\section{Commentary: The 250-mile radius rule in lung transplant donation: Even the best intentions have untoward consequences}

\author{
Gabriel Loor, MD, ${ }^{\mathrm{a}, \mathrm{b}}$ and Aladdein Mattar, $\mathrm{MD}^{\mathrm{a}}$
}

The United Network for Organ Sharing (UNOS) sought to promote the fair and appropriate distribution of donor lungs by changing its allocation system to prioritize recipients within a 250 -nautical-mile radius of the donor hospital. ${ }^{1}$ This change was made in response to a lawsuit over a recipient who wanted broader organ sharing. Previously, allocation had been based on the donor service area, such that a recipient's center would preferentially receive offers from a donor hospital that belonged to the donor service area, regardless of the distance between them.

When UNOS changed this policy in 2017, the effects of this change were almost impossible to predict because of the unequal distribution of donor hospitals throughout the United States. Some transplant centers have many donor hospitals nearby and few recipient centers, whereas others have few donor hospitals and several recipient centers. Some centers are located near the coastline, which reduces their donor offers even further.

Haywood and colleagues ${ }^{2}$ from the University of Virginia describe their real-world experience with the untoward effects of the 250-mile rule on small-to-moderatesized programs. Such programs are responsible for nearly half of the lung transplants performed in the United States. The authors provide data on their program, which services

From the a Division of Cardiothoracic Transplantation and Circulatory Support, Baylor College, of Medicine, Houston, Tex; and ${ }^{\mathrm{b}}$ Division of Cardiothoracic Transplantation and Circulatory Support, Texas Heart Institute, Houston, Tex.

Disclosures: Dr Loor is a consultant for Abiomed and his institution receives grant support for extracorporeal membrane oxygenation and cardiothoracic transplant research from Maquet, Medtronic, Transmedics, and St. Jude Medical. Dr Mattar reported no conflicts of interest.

The Journal policy requires editors and reviewers to disclose conflicts of interest and to decline handling or reviewing manuscripts for which they may have a conflict of interest. The editors and reviewers of this article have no conflicts of interest.

Received for publication Oct 9, 2020; revisions received Oct 9, 2020; accepted for publication Oct 17, 2020; available ahead of print Oct 31, 2020.

Address for reprints: Gabriel Loor, MD, Division of Cardiothoracic Transplantation and Circulatory Support, Texas Heart Institute, 6770 Bertner Ave, Suite, C-355K, Houston, TX 77030 (E-mail: Gabriel.Loor@bcm.edu).

J Thorac Cardiovasc Surg 2022;163:346-7

$0022-5223 / \$ 36.00$

Copyright (c) 2020 by The American Association for Thoracic Surgery

https://doi.org/10.1016/j.jtcvs.2020.10.072

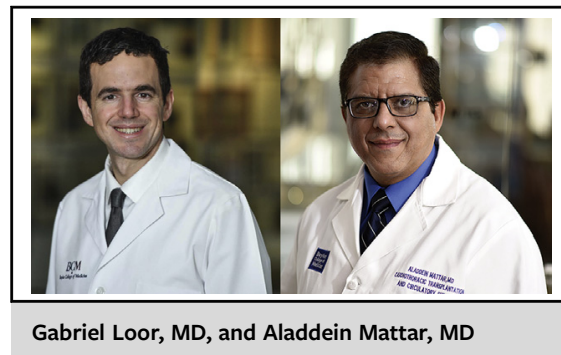

CENTRAL MESSAGE

In a retrospective single-center study representing a moderatesize lung transplant program, the 250-mile-radius rule did not translate into greater donor organ utilization or waitlist survival.

central and southwestern Virginia. Their 250-mile region is saturated with 8 other lung transplant centers.

The authors noted several effects associated with the change in the allocation system. Lung transplant volume increased $15 \%$. But at the same time, the number of local donors decreased 11-fold, organ travel time increased $62 \%$, and procurement costs increased $13 \%$. Most importantly, waitlist mortality increased 4.5 -fold. There was no increase in average total ischemic time, or in the rate of primary graft dysfunction or short-term mortality.

As in any retrospective study, it is always possible that other confounders were responsible for the findings. It is difficult to reconcile the increased transplant volume with the increased waitlist deaths. Typically, a center whose volume increases will see fewer deaths on the waitlist. In this series, patients who died on the waitlist had high lung allocation scores $(>80)$, which is a known risk factor. ${ }^{3}$ The authors also saw a $30 \%$ increase in listings after the policy change. Thus, it is conceivable that the increase in deaths on the waitlist was due not only to the allocation change but also to an increased listing of sicker recipients. Although the authors emphasize the increased costs, one could assume that the revenue from the increased transplant numbers could have made up for these costs.

Nonetheless, the findings show reasonable evidence of increased travel times and costs associated with the new policy. This, in combination with the increased waitlist mortality, provides sobering evidence that this policy change may have had the unintended consequence of decreasing organ availability and reducing the fairness of 
organ allocation. It suggests that small-to-moderate-size programs may be unfairly influenced. Larger programs have a tendency to transport organs across longer distances and accept greater numbers of extended criteria donors. They build systems around these practices and implement backup procurement teams, standby aircraft, and ex vivo lung perfusion (EVLP) technology.

This raises the issue of regionalization. Perhaps it is time that centers combine their strengths and reduce unnecessary competition that could adversely influence recipients. Unfortunately, such collaboration is difficult in our current health care system, in which even 2 transplant centers on the same block have different medical leadership boards, insurance contracts, and medical record systems, among other differences.

Another way to promote the fair and appropriate distribution of donor organs would be to increase the radius to 500 miles. This was not done by UNOS because of concerns over cold ischemic time. Although some authors have suggested that cold ischemic intervals can be safely extended beyond 6 hours, this notion is not universally accepted. ${ }^{4}$ However, even with the increased mile limit, a donor organ can be transplanted with an ischemic time $<6$ hours. Haywood and colleagues ${ }^{2}$ show that total ischemic time was kept the same even when donor organs traveled nearly twice the distance. This is probably because of the speed of air travel and, potentially, intraoperative procedural changes, which were not specified.

Portable normothermic EVLP with the Organ Care System Lung also reduces ischemia by perfusing and ventilating the lung throughout transportation. ${ }^{5}$ This benefit comes at a significantly increased procurement cost. Moreover, some regional perfusion centers receive an organ on ice, place it in static EVLP, and ship it back to a center for transplantation. This practice is based on studies showing no increase in adverse events with longer cold intervals and static EVLP. ${ }^{6}$ With present technology and practice patterns, increasing the radius to 500 nautical miles is probably a reasonable way to improve access to donor organs.

The study by Haywood and colleagues ${ }^{2}$ raises concern about untoward consequences of the new allocation system, which has potentially increased waitlist deaths and raised procurement costs at small-to-moderate-size centers. Policy changes in solid-organ transplantation should be considered carefully before implementation and then constantly reviewed to examine their effects. Despite the best of intentions, such changes may not always achieve what they are meant to.

Stephen N. Palmer, PhD, ELS, contributed to the editing of the manuscript.

\section{References}

1. Egan TM. From 6 years to 5 days for organ allocation policy change. J Heart Lung Transplant. 2018;37:675-7.

2. Haywood N, Mehaffey JH, Kilbourne S, Mannem H, Weder M, Lau C, et al. Influence of broader geographic allograft sharing on outcomes and cost in smaller lung transplant centers. J Thorac Cardiovasc Surg. 2022;163:339-45.

3. Valapour M, Lehr CJ, Skeans MA, Smith JM, Uccellini K, Goff R, et al OPTN/SRTR 2018 annual data report: lung. Am J Transplant. 2020;20(Suppl s1): 427-508.

4. Grimm JC, Valero V III, Kilic A, Magruder JT, Merlo CA, Shah PD, et al. Association between prolonged graft ischemia and primary graft failure or survival following lung transplantation. JAMA Surg. 2015;150:547-53.

5. Loor G, Warnecke G, Villavicencio MA, Smith MA, Kukreja J, Ardehali A, et al Portable normothermic ex-vivo lung perfusion, ventilation, and functional assessment with the Organ Care System on donor lung use for transplantation from extended-criteria donors (EXPAND): a single-arm, pivotal trial. Lancet Respir Med. 2019;7:975-84.

6. Yeung JC, Krueger T, Yasufuku K, de Perrot M, Pierre AF, Waddell TK, et al. Outcomes after transplantation of lungs preserved for more than $12 \mathrm{~h}$ : a retrospective study. Lancet Respir Med. 2017;5:119-24. 